\title{
Intraventricular and Intraatrial Conduction ECG Assessment
}

National Cancer Institute

\section{Source}

National Cancer Institute. Intraventricular and Intraatrial Conduction ECG Assessment. NCI Thesaurus. Code C111238.

An electrocardiographic assessment of the transmission of electrical impulses through the cardiac atria and ventricles. 